\title{
Late Complication due to Placenta Increta Left in Situ and Management Options
}

Zulfikir S, Al Bash M, Kakaria A, Gowri V, Saparamandu A and Al Kharusi L

College of Medicine and Health Science, Muscat, Sultanate of Oman

ABSTRACT

With the rising incidence of caesarean sections, the number of cases of placenta praevia and morbidly adherent placenta is increasing. Antenatal diagnosis and management in a tertiary care centre helps to reduce maternal and neonatal morbidity and mortality. We present a patient in whom the antenatal diagnosis of morbidly adherent placenta was missed due to late booking. In spite of the conservative approach at the time of caesarean section in the secondary care hospital, the patient presented with delayed complications and a total hysterectomy was performed.

Keywords: adherent placenta, hysterectomy, methotrexate, post partum haemorrhage

\section{INTRODUCTION}

Maternal and fetal morbidity and mortality from placenta praevia and placenta praevia accreta are considerable and are associated with high demands on health resource. ${ }^{1,2}$ With the rising incidence of caesarean sections combined with increasing maternal age, the number of cases of placenta praevia and its complications, including placenta accreta, will continue to increase..$^{3,4}$ We report a patient who presented with persistent vaginal bleeding two months after a caesarean section. During the caesarean section, a portion of the adherent placenta was left in situ. The antenatal diagnosis of placenta accreta/increta had been missed in this patient. The management options of abnormally-adherent placenta are discussed.

\section{CASE REPORT}

A 32-year-old para four had been admitted to a secondary care hospital with a history of on and off vaginal bleeding for two months after elective caesarean section (LSCS) and bilateral tubal ligation done for previous three LSCSs. During the caesarean section, she was found to have partial placenta accreta and the placenta could not be completely removed as it was partially adherent. She received three units of blood and four units of fresh frozen plasma intra operatively for an estimated blood loss of two and a half liters. Uterine packing (abdominal) was done to control the bleeding. The pack was removed after 24 hours and the patient was discharged after five days. A month later she was readmitted with fever and vaginal bleeding. She was treated conservatively with antibiotics and discharged home. She continued to have on and off vaginal bleeding for four weeks till the day of admission to our hospital.

On admission she was afebrile with mild lower abdominal tenderness. The uterus was not palpable per abdomen. On per speculum examination, the cervix was closed with minimal bleeding. Vaginal swabs were taken for

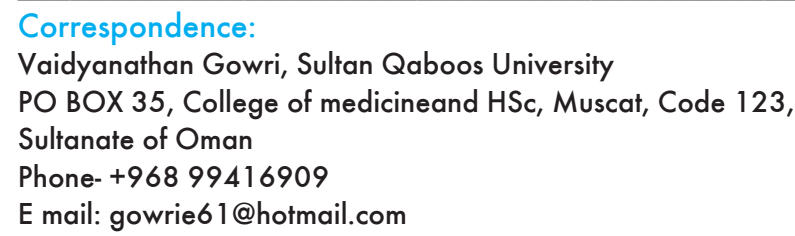


cultures. Bimanual examination revealed an anteverted uterus of about eight weeks' size with tender adnexa.

The blood work up revealed a hemoglobin of $8.8 \mathrm{gm} / \mathrm{dl}$, white blood cell count of $6.7 \times 10^{6}$, platelets $370 \times 10^{6}$ and B-HCG of $0.7 \mathrm{iu} / \mathrm{l}$. The coagulation profile, renal and liver function tests were within normal limits. A pelvic ultrasound followed by an MRI showed an intramural invasive mass invading the inferior segment of the uterus and extending to the right side reaching the subserosal uterine surface and distorting the uterine cavity, measuring $4.9 \times 5.2 \times 6 \mathrm{~cm}$, heterogeneous, with an area of peripheral focal enhancement and degenerated cystic areas (Figure 1). Both the bladder and pelvic walls had no gross invasion and the ovaries looked normal. The option of treatment with methotrexate was not suitable as the B -HCG report was negative. She was distressed with persistent bleeding for two months and as her family was complete, she wanted to have a hysterectomy. She underwent a total abdominal hysterectomy with conservation of the ovaries.

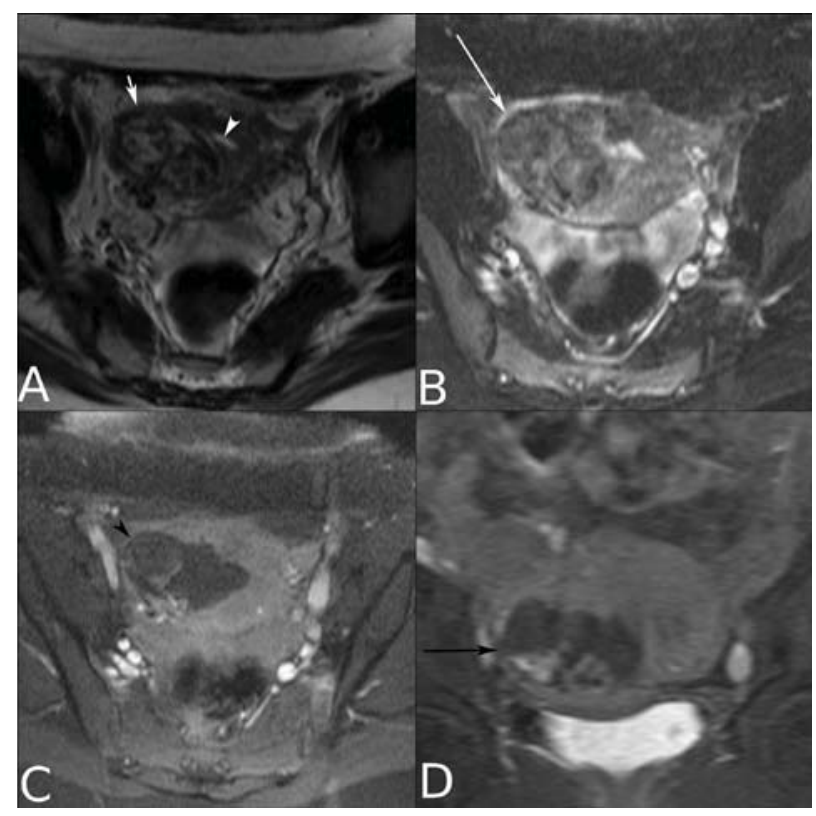

Figure 1. Fig $1 \mathrm{~A}$ and $\mathrm{B}$ show a mixed intensity lesion extending from the endometrial cavity (arrow head in A) through the myometrium to the serosal surface of the uterus (short white arrow in A and long white arrow in B). After enhancement by I/V gadolinium, the lesion shows decreased enhancement compared to the myometrium (C and D).

The operative findings were a fibrosed abdominal wall adherent to the anterior uterine wall. The uterus was bulky with a $4 \times 5 \mathrm{~cm}$ mass greenish blue in colour towards the right antero-inferior aspect of the uterus and the mass did not penetrate the serosa. The tissues were very friable; the bladder was adherent to the mass and was pulled up to the uterus but it was not invaded. Both adnexae were normal.

The histopathological examination confirmed placenta increta with no molar changes.

She was discharged after seven days, having been cured.

\section{DISCUSSION}

The risk of placenta accreta/ increta increases with number of previous caesarean sections (CS), one in six after two, one in four after three or four and one in two after five. ${ }^{3}$ The presence of placenta praevia and a history of previous caesarean should always raise the suspicion of placenta accreta/increta as well. Antenatal diagnosis of adherent placenta is possible with routine ultrasound imaging complemented with $\mathrm{MRI}$ in equivocal cases.

Management of placenta accreta/increta/percreta requires ${ }^{5}$ a multidisciplinary team approach -consultant obstetrician, anaesthetist, haematologist, and depending on the set up, surgeons, urologists, nursing and paramedical staff. An in-depth counselling of the patient about management and risks, informed consent for hysterectomy and at least four units of cross -matched blood and also blood products should be available.

Successful management of placenta accreta/increta/ percreta reguimes prevention and control of bleeding. In cases of pre-operatively diagnosed placenta accreta/ percreta, the caesarean section should be done by an expert consultant obstetrician. A mid line para median incision is recommended as the placenta might be adherent to the abdominal wall.5,6 The diagnosis of placenta accreta/increta was missed antenatally in our patient. The adherent portion of the placenta was left in situ to avoid further bleeding at the time of caesarean section. It is advisable to leave the adherent portions as trying to separate it can cause severe bleeding. ${ }^{7}$

Apart from the routine management protocol for the management of hemorrhage, uterotonic agents are also used which are of great help in reducing bleeding associated with atonic uterus. ${ }^{8}$

Specific techniques that have been described for the management of placenta accreta retrospective reviews and case reports include uterine and vaginal packing with gauze, balloon tamponade, the B-Lynch suture, vertical compression sutures and suturing an inverted lip of the cervix over the bleeding placenta bed. ${ }^{9}$ The treatment of severe postpartum haemorrhage using interventional radiology techniques and selective embolisation has 
been well reported ${ }^{10}$ but less clear is the value of prophylactic placement of arterial catheters in cases where placenta accreta is suspected antenatally. ${ }^{11}$ In the absence of severe bleeding, the placenta can be left in situ and managed expectantly with or without Methotrexate. Methotrexate to aid disintegration of placenta has been suggested by some but has not been accepted by others ${ }^{6}$.

Two types of conservative management other than methotrexate are possible in these women: a fully conservative management where the placenta is left in situ as reported by Welsh et $\mathrm{al}^{12}$ and a second method of resection of the myometrium and repair as described by Palacios et al. ${ }^{13}$

Though a fully conservative management is possible as suggested by Welsh et al, the retained placenta in uterus poses a risk of endometritis and Disseminated Intravascular Coagulation $(\mathrm{DIC})^{14}$. If the placenta is partially or completely left in situ, the woman should be warned of the risks of bleeding and infection postoperatively. Prophylactic antibiotics may be helpful in the immediate postpartum period to reduce this risk. Neither methotrexate nor arterial embolisation reduces these risks and neither is recommended routinely ${ }^{9}$. Though this patient had received antibiotics soon after surgery she was readmitted with fever and vaginal bleeding, needing further antibiotic therapy.

In cases of placenta praevia and accreta, there is a high risk of haemorrhage in subtotal hysterectomies with lower-segment invasions, and therefore, a total abdominal hysterectomy should be performed. ${ }^{15}$ Since the family was complete in our patient and as her quality of life was affected with on and off vaginal bleeding, a total hysterectomy was performed instead of uterine artery embolisation or total conservative management.

\section{REFERENCES}

1. Hall M. Haemorrhage. In Lewis G, Drife J,editors. Why Mothers Die 2000-2002. The Sixth Report of the Confidential Enquiries into Maternal Deaths in the United. Kingdom. London: RCOG Press 2004; 86-93

2. Salihu HM, Li Q, Rouse DJ, Alexander GR. Placenta previa: neonatal death after live births in the United States. Am J Obstet Gynecol 2003;188:1305-9.

3. Usta IM, Hobeika EM, Musa AA, Gabriel GE, Nassar AH. Placenta previa -accreta: risk factors and complications. Am J Obstet Gynecol 2005;193:1045-1049.

4. Gilliam M, Rosenberg D, Davis F. The likelihood of placenta previa with greater number of cesarean deliveries and higher parity. Obstet Gynecol 2002;99:976-80.

5. Steer PJ. The surgical approach to postpartum haemorrhage. The Obstetrician and Gynecologist (TOG). 2009;11:231-238

6. Premila S, Arulkumaran S. Massive and recurrent antepartum haemorrhage: Obstetrics, Gynaecology and Reproductive Medicine 2008; 18:11: 307-311.

7. Miller DA, Chollet JA, Goodwin TM. Clinical risk factors for placenta praevia-placenta accreta. Am J Obstet Gynecol 1997;177:210-214.

8. Oleen MA, Mariano JP. Controlling refractory atonic postpartum haemorrhage with Hemabate sterile solution. Am J Obstet Gynecol 1990;162: 205-208.
9. Royal College of Obstetricians and Gynaecologists. Placenta praevia, placenta praevia accreta and vasa praevia: diagnosis and management Third edition Jan 201126 pages. Green top Guideline no 27 London UK

10. Uchiyama D, Koganemaru M, Abe T, Hori D, Hayabuchi N. Arterial catheterization and embolization for management of emergent or anticipated massive obstetrical hemorrhage. Radiat Med 2008;26:188-197.

11. Bodner LJ, Nosher JL, Gribbin C, Siegel RL, Beale S, Scorza $W$. Balloon-assisted occlusion of the internal iliac arteries in patients with placenta accreta/percreta. Cardiovasc Intervent Radiol 2006;29:354-361.

12. Welsh AW,Ellwood D,Carter J, Peduto AJ, Veelago J, Bennett M. Opinion: Integration of diagnostic and management perspectives for placenta accreta Aust N Z J of Obstet Gynecol 2009; 49: 578-587

13. Palacios Jaraquemada JM, Pesaresi M, Nassif JC, Hermosid S. Anterior placenta percreta: Surgical approach, hemostasis and uterine repair. Acta Obstet Gynecol Scand 2004; 83: 738744

14. Timmermans S, van Hof AC, Duvekot JJ. Conservative management of abnormally invasive placentation. Obstet Gynecol Surv 2007;62:529-39.

15. Doumouchtsis SK, Arulkumaran S. The morbidly adherent placenta: an overview of management options. Acta Obstetricia et Gynecologica. 2010; 89: 1126-1133 